\title{
Hedging and the ignorance norm on inquiry
}

Yasha Sapir (University of Wisconsin-Milwaukee), Peter van Elswyk (University of Wisconsin-Milwaukee)

\author{
Penultimate Draft, Forthcoming in Synthese
}

\begin{abstract}
What sort of epistemic positions are compatible with inquiries driven by interrogative attitudes like wonder and puzzlement? The ignorance norm provides a partial answer: interrogative attitudes directed at a particular question are never compatible with knowledge of the question's answer. But some are tempted to think that interrogative attitudes are incompatible with weaker positions like belief as well. This paper defends that the ignorance norm is exhaustive. All epistemic positions weaker than knowledge directed at the answer to a question are compatible with having an interrogative attitude towards that question. We offer two arguments for this conclusion. The first is based on considerations about the role of hedging in inquiry. The second is conditional on considerations related to the aim of inquiry as a goal-directed activity.
\end{abstract}

\section{Introduction}

Inquiry driven by a question is governed by a variety of norms. It is impermissible, for example, to open a neighbor's packages just because one is curious about what is inside. There are other ways to quell boredom. When wondering about where to get coffee in Seattle, one should not proceed by reading every review of every coffee shop in the city. There are more effective strategies. This paper is about a subset of the norms that regulate inquiry as an activity.

We assume that some - if not all - inquiries are goal-directed activities in which participating agents aim to answer a question they are interested in. Such inquiries are driven by INTERROGATIVE ATTITUDES (IAS) like curiosity or wonder (Friedman 2013). ${ }^{1}$ A necessary condition of inquiry is therefore psychological. To inquire into a question is in part to direct the appropriate attitude to that question. IAs are what distinguish genuine inquirers from those who merely appear to be inquirers given their outward behavior.

The norms we focus on are those which prohibit occupying a particular epistemic position while possessing an IA. Since inquiry requires an IA, the norms prohibit conducting inquiry when in a particular position. Certain positions are

\footnotetext{
${ }^{1}$ A potential example of a different kind of inquiry is discussed by Kelp (forthcoming). Kelp suggests that in addition to inquiry whose target is settling a question, there is also inquiry whose target is understanding a phenomenon. Such inquiry differs potentially along two dimensions: it is phenomenon-directed as opposed to question-directed and not driven by an interrogative attitude but a desire or intention to understand. In this paper, our focus is on the former kind of inquiry. Though one of us is inclined to think that inquiry directed at understanding a phenomenon just is inquiry directed at settling a question, we sidestep getting entangled into issues in the epistemology of understanding.
} 
clearly not compatible with inquiry. For example, consider Nikolai's behavior in this case.

\section{LEFTOVER MILK}

Nikolai knows he has leftover milk. But he wonders whether he has leftover milk. So he opens up his fridge to check. Just as he knew there would be, an entire half gallon sits on the shelf.

Nikolai is acting improperly. As his inquiry is guided by an IA towards a question he wonders whether there is any leftover milk - he would utter (1) were he to narrate his state.

(1) \# I know there is leftover milk. But is there, I wonder?

But (1) is alarmingly defective. Nikolai's behavior in LEFTOVER MILK shows that he is not in good epistemic health.

To explain Nikolai's troubling behavior, we cast our lot in with Whitcomb (2017, $152)$ and Friedman $(2017,311)$ who each propose there is a norm prohibiting an agent from knowing the answer to a question into which they are inquiring. Where $p^{Q}$ indicates that $p$ is a complete as opposed to partial answer to a question $Q$, we present the norm thusly. ${ }^{2}$

IGNORANCE NORM (IGN)

One ought not inquire into $Q$ at $t$ and know $p^{Q}$ at $t$.

The norm explains what is amiss about Nikolai's behavior. $\mathrm{He}$ is behaving improperly because he is violating the norm prohibiting him from inquiring into what he already knows. ${ }^{3}$ An utterance like (1) is incoherent because it self-ascribes a violation of IGN.

A norm generates primary and secondary propriety (Williamson 2000, DeRose 2002 , a.o.). The primary impropriety of a prohibitive norm is a failing to abide by the prohibition. A secondary impropriety is an agent's being justified in believing they are failing to abide by the norm. For any norm, one ought not do what one is justified in regarding as a violation of the norm. Applied to IGN, an agent's act is primarily improper when the agent inquires into a $Q$ for which they know $p^{Q}$, and an act is secondarily improper when they inquire into a $Q$ and justifiably believe they know $p^{Q}$. Accordingly, IGN rules out not only those inquiries where inquirers already know what the answer is, but also those inquiries where inquiry justifiably believe that they are in such a position.

In addition to expanding the zone of impermissible inquiry, the primary/secondary distinction provides clarity about which violations of IGN are

\footnotetext{
${ }^{2}$ The proceeding discussion does not require us to take a side on what questions are. But it might help some readers to consider a Hamblin-style semantics on which an interrogative denotes a set of propositions that are its candidate answers. A complete answer to a question is then a proposition that entails the truth or falsity of every proposition in that set. In contrast, a partial answer is one that entails the truth or falsity of only some propositions in that alternative set.

${ }^{3}$ Whitcomb (2017) goes a step further to defend that IGN is a constitutive norm that individuates a speech act of asking. However, we are generally skeptical that speech acts are individuated by constitutive norms. For reasons to be skeptical that assertion is individuated by a constitutive norm that apply to asking as a speech act, see Maitra (2011) and Kelp and Simion (2020).
} 
typically excusable. Let WELL-INTENTIONED INQUIRY name inquiries wherein an agent violates IGN primarily but not secondarily because they falsely yet justifiably believe they do not know. ${ }^{4}$ Typically, well-intentioned inquiry is excusable. IGN is violated but agents are still doing their best.

An illustration is provided by considering a potential counterexample. Archer (2018, 601-604) observes that an agent who knows $p^{Q}$ can wonder $Q$ without being blameworthy if their knowledge is not "cognitively available.” He thereby concludes that IGN is no norm at all. But that conclusion is too quick given the primary/secondary distinction. An alternate explanation is that the agent is not blameworthy because they are well-intentioned. They are not like Nikolai who is aware that he knows but inquires anyway. From their point of view, their inquisitive behavior is coherent and natural. ${ }^{5}$

IGN is far from being the most surprising norm on inquiry. But it provides a starting point from which to explore which epistemic positions are compatible with inquiry guided by IAs. Consider a particular epistemic position $V$ like having a hunch, believing, having justified belief, being nearly certain, and so on. If $V$-ing $p^{Q}$ is defective or improper while inquiring into $Q$, then there is plausibly a norm prohibiting as much. That norm would fill out the schema below by replacing $V$ with the position being considered.

\section{NORM SCHEMA}

One ought not inquire into $Q$ at $t$ and $V p^{Q}$ at $t$.

In this paper, we defend that inquiry is permissible alongside every epistemic position that's not already ruled impermissible by IGN. ${ }^{6}$ That is, we argue for IGN's exhaustivity. There is no true instance of the norm schema where $V$ stands in for a position that is not knowledge. As long as an agent's position falls short of knowledge and the agent is not justified in taking themselves to know, inquiry into a particular question is permissible.

To make our case, Friedman (2019a) is our point of departure. She defends an instance of the norm schema where full belief in $p^{Q}$ is improper with inquiry into $Q$. The same norm is also endorsed by McGrath (forthcoming) and defended by Millson (forthcoming).

\section{DON'T BELIEVE AND INQUIRE (DBI)}

\footnotetext{
${ }^{4}$ A nearby notion is WELL-INTENTIONED TERMINATION. Though IGN, as a wide-scope norm, is silent on when to initiate or terminate inquiry, one might propose a norm according to which one must terminate inquiry only when one knows a complete answer. Well-intentioned terminating would then be when one stops inquiring because they believe they know an answer. Whitcomb (2010, 677-678) endorses such a termination norm and convincingly argues that Gettiered inquirers are well-intentioned. They terminate inquiry impermissibly, but their epistemic wrong-doing is excusable because they are justified in believing they know.

${ }^{5}$ This reply pairs well with a responsibility-based conception of self-knowledge. If awareness of one's attitudes involves regarding them as commitments or states for which one is responsible (Burge 1996, Bilgram 2006), attitudes of which one is unaware are not attitudes that one can attempt to bring into compliance with norms on inquiry.

${ }^{6}$ IGN is compatible with an array of stronger epistemic norms such as norms prohibiting inquiry into what we know we know or into what is certain for us. But given standard thinking about higher-order knowledge and certainty, the stronger norms will just prohibit a proper subset of the actions IGN already prohibits. For this reason, we ignore stronger norms.
} 
One ought not inquire into $Q$ at $t$ and believe $p^{Q}$ at $t$.

The existence of DBI is incompatible with our contention that IGN is exhaustive. Our plan is to present two objections to DBI, and then to show how those objections generalize.

Our first objection to DBI involves cases of hedging. When speakers hedge, they can believe $p^{Q}$ even while properly inquiring into Q. DBI mishandles such cases by predicting they are impermissible. The second objection is that, if the goal of inquiry is to know a complete answer, then IGN but not DBI elucidates why inquiry and the epistemic position identified by each are jointly improper. Each objection motivates our broader thesis that IGN is exhaustive: inquiry with positions weaker than knowledge is permissible, at least in cases where such inquiry isn't secondarily improper from the point of view of IGN.

Here is how we proceed. In §2, we consider the data which Friedman (2019a) provides to motivate DBI, and argue that IGN explains the data as well. Hence there is no explanatory need to posit an additional norm beyond IGN. Next, in $\S 3$, we argue that DBI but not IGN mishandles hedging. In $\S 4$, we present our second objection to DBI related to the goal of inquiry. We conclude in $\S 5$ by discussing how our objections to DBI apply to other norms prohibiting an agent from inquiring while occupying an epistemic position weaker than knowledge.

\section{Belief and inquiry}

Friedman (2019a) motivates DBI on the basis of its ability to explain contrasting cases, infelicitous discourses, and high-stakes cases. In this section, we briefly canvass this data and argue that IGN explains the data just as well. Accordingly, there is zero reason to posit DBI in addition to IGN.

\subsection{Inspector Morse}

Friedman presents three cases in which an Inspector Morse occupies a different position towards a proposition $p^{\mathrm{Q}}$ : ignorance, knowledge, and false belief. For each, she considers whether it would be proper for Morse to also have an IA towards $Q$. The idea is that by learning whether a position is compatible with an IA, we also learn whether it is compatible with inquiry. Friedman's key claim is that having an IA is proper when Morse's attitude is ignorance, but improper when Morse's attitude is knowledge or belief. DBI captures as much.

That is her case-based argument. But let's move more slowly and consider the cases.

\section{NORMAL MORSE}

Morse is woken up by his telephone ringing in the early hours of the morning - a doctor in Oxford has been shot through her window while having dinner last night. Morse pulls himself together and heads to the scene of the crime. This is a normal case for Morse and he engages in a perfectly normal inquiry into who killed the doctor. He searches the scene, talks to potential witnesses, and so on. Then he discovers that the doctor was having an affair with the master of Lonsdale College, so he takes his investigation over to the college. And things go as expected there as well: he talks to more people, does more 
looking around, draws a few inferences, stops at the pub and eventually solves the crime (Friedman 2019a, 300).

In this case, Morse doesn't know who killed the Oxfordian doctor. As such, Friedman notes that it is proper to imagine him wondering who the killer was. Our reaction to the case is evidence that ignorance toward the complete answer to a question is compatible with an IA towards that question.

The next Morse case - call it KNOWING MORSE - is just like the first one, save for one big difference: Morse himself is the killer, and he's desperate to cover up his tracks while appearing to conduct an investigation. Friedman again asks whether Morse can properly adopt an IA toward who killed the doctor. For this case, however, she does not think he can. After all, it is hard to understand how this second Morse could coherently wonder who the murderer is, given that he already knows that murderer is he himself. IAs such as wonder or curiosity do not sit nicely with the fact Morse knows. Our reaction to KNOWING MORSE is evidence that knowing the complete answer to a question is incompatible with an IA.

The final case is BELIEVING MORSE. It is like the second but with a twist. Morse again wakes up believing that he killed the doctor in Oxford, but in fact it's all an illusion that is a result of "pseudo-memories implanted in his mind by a crafty old nemesis". Though Morse believes he knows who the murderer is, that in fact isn't so (Friedman 2019a, 301). Once more, Friedman asks whether it is proper for Morse to have an IA toward the investigative question. And again, as with the last case, the verdict is negative. Thus it would seem that having an IA is improper with both knowledge of the complete answer, as is evidenced by KNOWING MORSE, and belief in the complete answer, as is evidenced by BELIEVING MORSE.

BELIEVING MORSE helps explain why Friedman proposes DBI. Whereas both norms explain why Morse having an IA in KNOWING MORSE does not seem proper, Friedman regards DBI as having an easier time explaining why Morse having an IA in BELIEVING MORSE is improper. But Morse's predicament can be explained by IGN via the primary/secondary distinction introduced at the start of this paper. Were Morse to have an IA in BELIEVING MORSE, he would violate IGN in a secondary manner. We submit that he justifiably believes he knows a complete answer to his inquiry because of the pseudo-memories planted into his head. As a result, inquiring into who killed the doctor would place him in the improper position of possessing an IA while believing he knows the answer.

\subsection{Defective discourses}

Friedman's second argument for DBI stems from the infelicity of discourses pairing an assertion that $p^{Q}$ with an IA directed at $Q$. The examples Friedman $(2019 a, 305)$ gives are (2) through (4) below.

(2) \# Morse killed the doctor, but I wonder who killed the doctor (/whether Morse killed the doctor/...)

(3) \# All four Beatles went to the party, but I'm curious about which Beatles went to the party (/whether all four Beatles went/ ... ) 
(4) \# We should turn right here, but I'm deliberating about which way we should turn (/whether we should turn right here/ ... )

Each discourse is defective while still being meaningful and grammatical. That defectiveness plausibly traces back to the epistemic position they publicize. Speakers who utter such discourses are not epistemically behaving as they should. We need an explanation for why. Friedman adopts the common view that assertions express belief. Consequently, a person who asserts $p^{Q}$ while disclosing that they have an IA toward $Q$ reports they believe the complete answer to the question into which they are inquiring. The discourses are defective because they state outright that DBI is violated by the speaker.

But IGN enables a similar explanation with a minor adjustment. The adjustment is a familiar one from the literature on assertion: the first conjunct represents the speaker as knowing as opposed to merely believing. (2), (3), and (4) are thereby defective because the speaker is indicating they are violating the prohibition to not inquire and know a complete answer.

\subsection{High stakes cases}

The final source of data involves high stakes cases where it is practically important that an agent correctly answer a question. Friedman (2019a) identifies three key features of such cases. First, subjects in high stakes cases are subjects who must double-check their preliminary answers to a question. Call this the DOUBLE-CHECKING CONDITION. Second, subjects in high stakes cases are in weak epistemic circumstances. Call this the WEAKNESS CONDITION. Both features seem to be genuine elements of familiar high stakes cases.

For an illustration of these features, consider a variant on the story of Hannah, a person whose financial woes were first documented by DeRose (1992).

\section{CHANGING STAKES HANNAH}

Hannah wants to know if the bank will be open on Sunday or whether she ought to cancel her meeting and go today. She remembers that she was able to go to the bank on Sunday a few months ago. The memory makes her rest easy and she resolves not to cancel the meeting. But then she remembers that it is very important that she cash her check by Sunday because she recently used her new credit card to go on book-buying binge in Boston. Given the stakes of the situation, she decides to double check the bank's hours of operation by going to the bank's website on her phone. Sure enough the bank's website reports that the bank will be open. Hannah breathes a sigh of relief, and jumps on her motorcycle to go to her meeting.

Both of the features highlighted above are elements of CHANGING STAKES HANNAH. Even though Hannah initially arrived at the belief that the bank will be open on Sunday, her subsequent recognition of the high stakes led her to double-check. Her grounds for double-checking seem to be rational in part because her recognition of the stakes of her situation weakened her epistemic situation. She consequently needed more evidence than just her memory.

The third feature is perhaps more controversial than the other two features. Friedman $(2019 a, 305)$ maintains that subjects in high stakes cases who have to double check the answer to a question shouldn't regard any answer to that question as true until they finish double checking. Call this the SUSPENDING CONDITION. 
Consider Hannah in CHANGING STAKES HANNAH just before she double-checks the bank's hours on her phone. Friedman judges that prior to double-checking, Hannah shouldn't have a belief in a complete answer.

To explain such a case, Friedman $(2019 a, 305)$ assumes an additional principle. The principle is a conditional with DBI as a conjunct in its antecedent.

\section{OBLIGATORY INQUIRY}

If one ought not both inquire into $Q$ at $t$ and believe $p^{Q}$ at $t$ (i.e. DBI), and one ought to inquire into $Q$ at $t$, then one ought not believe $p^{Q}$ at $t$.

Friedman's strategy is to use DOUBLE-CHECKING CONDITION in concert with this principle and DBI to explain the SUSPENDING and WEAKNESS CONDITIONS. Here's how it goes. As per the DOUBLE-CHECKING CONDITION, Hannah should double-check. Given DBI, the antecedent to the conditional is then satisfied. Accordingly, Hannah should not believe her prior answer to whether the bank is open. DBI therefore helps explain two of the highlighted conditions. First, DBI explains the SUSPENDING CONDITION with the help of the conditional principle and the DOUBLE-CHECKING CONDITION. Second, DBI thereby explains the WEAKNESS CONDITION. Since agents who have been compelled to suspend belief are in weaker epistemic circumstances than agents who are permitted to still believe an answer, DBI explains the WEAKNESS CONDITION as a consequence of its having first explained the SUSPENDING CONDITION.

Since knowledge requires belief, IGN in conjunction with OBLIGATORY INQUIRY can explain both the weakness and suspending conditions in the same manner. But we want to explore another explanation. We are not convinced that the SUSPENDING CONDITION is a genuine feature of every high stakes case. Consider the following modification to the case.

\section{HESITANT HANNAH}

Hannah wants to know if the bank will be open on Sunday or whether she ought to cancel her meeting and go today. She remembers going to the bank on Sunday a while ago, but knows that the stakes of the situation are high. So she decides to double check the bank's hours of operation by going to the bank's website on her phone. At that very moment, Hannah's friend Ari calls. Ari asks Hannah if she thinks the bank will be open on Sunday. Hannah responds as follows:

(5) I believe that it is. But there is a lot that hangs on being right, at least for me, so I was just now going to double-check on their website. I will message you if they're closed.

In the situation described, Hannah retains her belief that the bank will be open on Sunday even though she is in the midst of double-checking as much. Accordingly, high stakes cases do not mandate that an agent like Hannah drop her belief. So we do not think a norm like DBI or IGN has to explain the SUSPENDING CONDITION, especially by way of an auxiliary principle about obligation.

Even if the SUSPENDING CONDITION is not a genuine feature of high stakes cases, the reply might be given that double-checking often correlates with the agent dropping her original belief. Perhaps DBI can better help explain the correlation. After all, it is easy to imagine Hannah in the original case dropping her belief after realizing that it is important to know the answer to her question. 
IGN is similarly helpful in explaining the correlation due to how belief and knowledge themselves correlate. First, dropping belief correlates with dropping knowledge. Since knowledge requires belief, dropping belief in a complete answer drops knowledge too. Second, dropping knowledge often correlates with dropping belief. Consider CHANGING STAKES HANNAH once more. Hannah's realization that the stakes are higher than she thought leads her to reevaluate whether she knows whether the bank is open on Sunday. Where once she thought she knew as much, she now is less confident. That change is brought about by her awareness of the stakes. The particularities of how the latter leads to the former are very controversial and not something we need to adjudicate. Regardless of how they are understood, the process that leads Hannah to doubt that her belief counts as knowledge will often lead her to drop the belief altogether. For example, suppose Hannah stops taking herself to know because she regards her evidence as weaker than initially thought. Regarding her evidence as weaker will often prompt her to stop believing simpliciter that the bank is open.

\section{Hedged belief and inquiry}

We now turn to the case against DBI. The first is related to the role played by hedging in joint inquiry. We defend two main claims. The first is that hedged statements can entail that the speaker believes a proposition. The second is that hedged statements do not settle inquiry. DBI's mistake is that it predicts certain instances of hedging to be epistemically improper when they are not.

\subsection{Hedging and belief}

Hedging is often characterized as weakened commitment or diminished responsibility to a proposition expressed (Fraser 2010, McCready 2015, Benton and van Elswyk 2020). For the purpose of this paper, we offer less committal characterization in terms of the strength with which a speaker presents a proposition. A speaker hedges by using a declarative sentence that contains an epistemic term that participants understand as weakening the strength with which the speaker presents the proposition expressed. In a slogan, hedges attenuate presentational strength. That strength may or may not essentially involve normative notions. On that we do not take a side.

Our sole focus is on the attitude verb believe. ${ }^{7}$ It can be used to hedge in either a matrix or parenthetical position. In a matrix position, the hedging use is easiest to detect in a question-answer discourse. To illustrate, compare the following exchanges.

\footnotetext{
7 A speaker can hedge without using an attitude verb. Likewise, a speaker can hedge without using believe. We focus on believe to have a clear, unambiguous counterexample to DBI. For example, Millson (forthcoming) presents a challenge for DBI involving confirmation-seeking expressions as opposed to hedging expressions. His way around the challenge is to deny Lockeanism about belief and maintain that confirmation-seeking expressions express credences as opposed to full belief in a proposition. No similar response will be available here because hedging with believe entails speaker belief. Admittedly, hedging with believe is less common than hedging with think. But there is reason to think believe is as weak as think. See Hawthorne et al (2016) and Rothschild (forthcoming). Then think-based examples would be equally problematic for DBI.
} 
(6) Do you believe there is leftover milk?

(7) I believe that there is leftover milk.

(8) Is there leftover milk?

(9) I believe that there is leftover milk.

Sentences (7) and (9) are identical in appearance, but the contribution of believe can be interpreted differently. In reply to (6), a question explicitly about the speaker's beliefs, believe does not weaken strength. It contributes to the speaker's primary contribution. However, believe can be understood differently in (9). ${ }^{8}$ The question it answers is not about the speaker's beliefs. What is the primary contribution of (9) is that there is leftover milk, and believe weakens the strength with which the speaker presents that contribution.

A parenthetical verb differs from a matrix verb in that it can appear in either an initial, medial, or sentence-final position. Believe is one of the attitude verbs that can occupy a parenthetical position. (10) and (11) are answers to (6).

(10) There is, I believe, leftover milk.

(11) There is leftover milk, I believe.

Like the instance of believe in (7), the instances in (10) and (11) can be interpreted as not contributing to what the speaker is putting on the record. When interpreted in such a way, they are interpreted as hedges that weaken the strength of presentation.

It is a platitude that believe in matrix position within a declarative entails that the sentence's subject believes. Believe-parentheticals are trickier because their contribution is clearly different from believe in matrix position. But they still entail subject belief. If believe-parentheticals did not, we could construct felicitous discourses consisting of two parts: first, a statement that $p$ qualified with a believe-parenthetical and, second, a disavowal of belief in $p$. However, we cannot. Discourses like (12) are contradictions.

(12) \# There is leftover milk, I believe. But I don't believe that there is leftover milk.

That such a contradiction is expressible is evidence that the believe-parenthetical is entering into entailment relations with the believe in matrix position in the discourse. ${ }^{9}$ Indeed, every compositional semantics for parenthetical verbs we are

\footnotetext{
${ }^{8}$ We take the data to sufficiently motivate that believe in matrix position can be interpreted as a hedge and remain neutral on how best to explain how it is interpreted as such. Presumably, the hedging interpretation is arrived at pragmatically. The agent asking (6) recognizes that (7) is not an answer in a strict sense. Assuming a Hamblin semantics for questions, for example, (7) does not entail the truth or falsity of any of the propositions in (6)'s denotation. The asking agent then attempts to discern why the speaker of (7) would have said what they did. The hedging interpretation will often be the best explanation.

${ }^{9}$ A referee suggests an alternative diagnosis. If the negation in the continuation is interpreted in the embedded clause (i.e. neg-raising), then (12) could be paraphrased as this: There is leftover milk, I believe, but I believe there is not leftover milk. This does not express a contradiction. Instead, it expresses that the speaker is in an irrational state. With this diagnosis, one might argue that believe-parentheticals actually expresses an attitude weaker than belief like suspicion. After all, it would still be defective to suspect what you believe is false. However, the neg-raising interpretation can be blocked and a contradiction still results. The easiest way to block neg-raising is to add
} 
aware of assigns them meanings in which they entail that the speaker occupies the attitude or epistemic position indicated by the parenthetical verb. ${ }^{10}$

Our objection does not require more to be said about what it means for epistemic terms to weaken the strength with which a proposition is expressed. Nor does it require the details of how that weakening effect is linguistically produced. Specifying as much requires a complete epistemology and semantics for hedging and offering as much is not our aim. Whatever the finer details of hedging, the examples above show that the verb believe is used to hedge and that such uses of the verb entail that the speaker believes. ${ }^{11}$

\subsection{Hedging and inquiry}

The idea that hedged statements do not settle inquiry can be found in Adler's (2006, 235) brief discussion of qualified assertions:

Epistemically qualified assertions are not truly assertions. Toulmin captured this crucial point without, however, developing it: "To say 'Probably $p$ ' is to assert guardedly, and/or with reservations, that $p$ (1950: 85)." Since the central aim of the exchange is to transmit the information that $p$ (all-or-none), the qualified expression (manifestly) falls short. If Harry asks Sally "Whose turn is it to walk the dog?" and Sally responds "I'm pretty sure it's your turn," the task remains unsettled. Sally's guarded assertion is acknowledgement of unsuccessful communication.

In contrast to unqualified statements, hedged statements leave inquiry unresolved. Consider each side of Adler's example. On the speaker's side, hedging enables Sally to not determine for Harry whose turn it is to walk the dog. Notice that, if she is

intonational focus onto the matrix verb (Gajewski 2007, Romoli 2013). When added to (12), infelicity still results.

$(12)^{\star} \#$ There is leftover milk, I believe. But I don't [believe $]_{\mathrm{F}}$ that there is leftover milk.

Additionally, the insertion of a temporal adverb like still between negation and believe also problematizes neg-raising.

$(12)^{* *}$ \# There is leftover milk, I believe. But I don't still believe there is leftover milk.

Interpreted with neg-raising, the continuation $(12)^{* *}$ states that the speaker still believes there is not leftover milk. But that interpretation is hard to access. Finally, we can construct a similar contradiction without negation.

$(12)^{\star * \star}$ \# There is leftover milk, I believe. But I refrain from believing there is leftover milk.

The phrase refrain from replaces negation in $\left(12^{\star * *}\right)$. This phrase does not license a raised interpretation but still yields a contradiction. An agent cannot both $V$ and refrain from $V$-ing. These considerations show that the alternative diagnosis is not as explanatory as the straightforward proposal that believe-parentheticals express belief.

${ }^{10}$ See Asher (2000), Murray (2017), and van Elswyk (forthcoming).

${ }^{11}$ It is important to distinguish what hedging can reflect about the speaker's position and what hedged testimony may entitle for a hearer. We have defended that a speaker can hedge and believe. This is fully compatible with hedged testimony not entitling full belief. For example, Jackson (2020, §3.3) suggests that hedged testimony only entitles a hearer to adjust their credences as opposed to forming a full belief in what is stated. 
wrong about whose turn it is and Harry learns as much by checking past text message conversations, she is not fully responsible for the wrong answer. She can always defend herself by pointing out that she didn't speak without qualification. She said merely she was "pretty sure." As a result, Harry is at least partially responsible for treating "I'm pretty sure it's your turn" as settling. He took a non-settling answer and treated it as if it were a settling answer.

On the hearer's side, the hedge has a similar effect. Since the qualified statement does not settle inquiry, it invites Harry to seek out an answer based upon a different source of evidence. Normally, continuing inquiry after receiving an unqualified answer requires rejecting or ignoring the person's conversational contribution. But this is not the case for Harry. Harry had continued his inquiry after hearing from Sally by checking their past text message conversations, Harry would not be understood as ignoring or rejecting Sally's contribution. Her contribution would be treated as providing evidence relevant to the question but as falling short of settling his inquiry. ${ }^{12}$

That hedged statements fail to settle inquiry can further be illustrated by adjusting the example with which we began this paper. In the process, we can arrive at a counterexample to DBI.

\section{FORGOTTEN GLASSES}

Boris Stepanovich's wife Anna Igorovna asks Boris if there's still milk in the fridge. Boris wonders this too. So he opens the fridge to check. However, as he is opening the fridge, he realizes that he has forgotten his spectacles. Boris and Anna maintain a Good Russian Household, and therefore consume both milk and kefir, a dairy product that is housed in cartons that resembles the cartons that house milk. Boris squints and comes to believe that the carton seen in the fridge contains milk. Nonetheless, Boris still wonders if what's in the fridge is milk rather than kefir. So, Boris closes the fridge and says to Anna one of the following:

(13) I took a look in the fridge. I believe that there is milk. However, I forgot my glasses and it was hard to tell if what I saw was milk or kefir. So I don't really know. I'm gonna find my glasses and then check again whether there is milk.

(14) I took a look in the fridge. There is milk, I believe. However, I forgot my glasses and it was hard to tell if what I saw was milk or kefir. So I don't really know. I'm gonna find my glasses and then check again whether there is milk.

There is nothing defective about Boris's report to Anna. Grammar permits him to say as much and, whatever the epistemic norms of inquiry are, they too permit him to act as he does. Boris conveys that his inquiry is not yet over through hedging.

Therein lies the problem for DBI. Whether the hedge occurs via believe in a matrix like (13) or parenthetical position like (14), Boris can express belief in a complete answer to a question $Q$ and still permissibly continue inquiry into $Q$. But that is what is ruled out by DBI. It mistakenly predicts that the epistemic alarm bells should be ringing with what he has said and done.

${ }^{12}$ Both of these observations about the speaker and hearer obtain even if the context has incredibly low stakes. This suggests that hedged assertions are not on enough to settle inquiry regardless of the stakes. To be sure, Harry could proceed as if Sally's reply were sufficient. But, in doing so, Harry would be acting in a way that goes beyond what Sally actually contributed to the conversation. 
Hedging counterexamples are easily reproducible. The last example was a polar question allowing only a positive or negative answer. As such, Boris expressed belief in a complete answer by expressing belief in any direct answer to the question. However, we can illustrate the same point with a constituent question by inserting the adverb only into the hedged answer.

\section{NEW YEAR'S PARTY}

Nikolai Mikhailovich hosted a party to celebrate the start of the new year. Anna Igorovna, who didn't attend, is later asked by a mutual acquaintance about who attended the party apart from Nikolai. Anna considers the question, and offers one of these replies:

(15) Only Borya was at the party, I believe. But I don't know that. So I can't help but wonder myself which people attended the party.

(16) Only Borya was at the party, I believe. But I don't know that. So let's ask Kolya, the party's host, to figure out who was at the party.

The above discourses, which feature parenthetical verbs as opposed to matrix ones, represent the speaker as failing to comply with DBI. For they each represent their speaker as believing a complete answer to a question they are still actively inquiring into. DBI predicts that the above data should display epistemic impropriety. And yet, what Anna states is beyond reproach.

In a footnote, Friedman $(2019 a, 313)$ claims that sentences of the form " $S$ thinks/believes $p$ and $S \phi$ s Q", where $\phi$ stands for an interrogative attitude, indicates that $S$ is in a confused state and not "epistemically thriving." 13

(17) ? I believe there is leftover milk and I wonder whether there is leftover milk.

We acknowledge that discourses like (17) are awkward. ${ }^{14}$ But they are difficult to interpret in two important respects. First, the contribution of believe is ambiguous. We cannot tell whether the verb is in a parenthetical or matrix position and, if the latter, whether the verb is to be interpreted as a hedge. Second, the epistemic position of the speaker is not clear. Discourses like (17) do not state outright that IGN is violated. But given the primary/secondary distinction, (17) might still reflect a violation of IGN in a secondary way if the speaker believes they know there is leftover milk and still wonders if there is.

For these reasons, discourses like (17) are not probative. Only when what is left open by (17) gets resolved can we assess whether IGN makes accurate predictions about felicity. Fortunately, IGN does predict accurately once we fill in the blanks. Compare (17) alongside (16) from earlier. In (16), believe is behaving as a hedge because it is in a parenthetical position. Since a declarative represents the speaker as believing its content, But I don't know that clarifies that the speaker believes they do not know. Accordingly, the speaker is not in a situation where they violate IGN in a secondary manner.

${ }^{13}$ Archer (2018) considers discourses like I am wondering whether the bank is open, but I believe it is and argues that they problematize the thesis defended in Friedman (2017) that possessing an interrogative attitude requires suspending belief. We do not share this judgment. We submit that the difference between his discourses and (13) and (14) is that the latter are clearly hedges.

${ }^{14}$ Note that (17) improves if and is replaced by but. Since but merely indicates contrast between the conjuncts, (17) is at least partly odd for reasons having nothing to do with inquiry. 
(16) Only Borya was at the party, I believe. But I don't know that. So let's ask Kolya, the party's host, to figure out who was at the party.

The felicity of (16) is to be expected given IGN. There is nothing wrong with believing $p^{Q}$ and inquiring into $Q$ as long as one does not take one's belief to constitute knowledge.

But now compare (17) to (19). The believe below is in matrix position where it is not a hedge. The discourse also clarifies that the speaker believes they know a complete answer as conveyed by the continuation "In fact, I know that." As a result, (19) is at least a secondary violation, if not a primary violation.

(18) Do you believe there is leftover milk?

(19) \# I believe that there is leftover milk. In fact, I know that. But I wonder whether there is leftover milk.

So another way of filling in the blanks left open by the underspecified (17) pose no problem for IGN. The above is predicted to be infelicitous by IGN as a secondary violation.

\subsection{Knowledge and hedging}

DBI mishandles hedges because it erroneously predicts that hedged statements settle inquiry as long as the speaker believes. IGN inherits this problem only if hedges entail speaker knowledge. They do not. Consider (21) and (22).

(20) Who was at the party?

(21) I know that only Boris was at the party.

(22) \# Only Boris was at the party, I know.

(21) is felicitous and not a hedge whereas (22) is neither felicitous nor a hedge. Unlike believe in our earlier examples, (22) shows that the inclusion of know in matrix position is not interpreted as weakening the strength with which the proposition is presented. In a parenthetical position, know is usually infelicitous (Slote 1979, Rooryck 2001, Benton 2011). In the rare case it is not, know-parentheticals still do not weaken the presentation strength of the statement.

IGN therefore fairs better than DBI when it comes to hedging because hedges do not express knowledge. More than that, IGN pairs elegantly with the view of hedging found in Benton and van Elswyk (2020). They hold that hedges weaken the strength with which a proposition is presented by representing an epistemic position weaker than knowledge. The use of an unhedged declarative represents the speaker as knowing the proposition expressed. The function of hedging is to stop or eliminate the representation of knowledge typically by representing the position indicated by the hedging term.

A helpful illustration is given by challenge data. How participants challenge helps reveal what epistemic position is represented by a declarative's utterance. Williamson (2000) notes that challenges to (23) like (24) support the claim that unhedged declaratives represent speaker knowledge.

(23) Only Boris was at the party. 
(24) How do you know that? / You don't know that!

However, the same challenges are infelicitous in response to a hedged declarative like (25).

(25) Only Boris was at the party, I think.

(26) \# How do you know that? / You don't know that!

The reason why is that knowledge is no longer represented. Unlike (23) where the speaker represents themselves as knowing that only Boris was at the party, the speaker of (25) merely represents themselves as thinking as much. The proper challenge given the position represented would be Why do you think that? or something analogous that corresponds to the position indicated by the hedging term at the end of the sentence.

The knowledge-centric view of hedging provides further clarity about why hedged discourses are felicitous. A hedged statement cannot represent knowledge. So a hedged discourse never states a primary violation of IGN. Additionally, speakers who choose to hedge choose not to represent knowledge. Assuming the hedging is sincere in that the speaker is not attempting to mislead others about the strength of their epistemic position, hedging is usually accompanied with a belief that the content of the hedged statement is not known. If it were, the speaker would have not hedged. So a hedged discourse, if sincere, does not qualify as a secondary violation of IGN either.

The knowledge-centric view of hedging also sheds light on additional data favoring the explanatory primacy of IGN. In discussing which epistemic norms might constitute the speech act of asking, Whitcomb $(2017,159)$ presents what we call DECLINING DATA. Where $V$ once again stands in for an epistemic position like having a hunch or strongly believing, consider the schematic reply below for a question $Q$.

DECLINE SCHEMA

I can't answer that. But I $V$ that the answer is $p^{Q}$.

Not every way of filling out the schema produces a coherent discourse. Suppose the question being discussed is who was at the new year's party, as set-up by NEW YEAR'S PARTY. Replacing $V$ with knowledge produces incoherence. Not so for substitutions of $V$ that specify a weaker epistemic position not prohibited alongside inquiry by IGN.

(27) \# I can't answer that. But I know that the answer is that only Borya was.

(28) I can't answer that. But I believe that the answer is that only Borya was.

(29) I can't answer that. But I have a hunch that the answer is that only Borya was.

Whitcomb takes the data as evidence that IGN as opposed to a weaker norm constitutes a speech act of asking.

But note that the declining data also doubles as problematic data for DBI. Agents who cannot answer a question $Q$ are agents for whom $Q$ remains open: they're capable of further inquiry into what the answer is. For agents in such situations, therefore, it is natural to characterize such openness by ascribing interrogative attitudes to them. These are agents who still wonder and are curious. But if their still 
being capable of further inquiry is what motivates the judgment that it is coherent that they cannot answer the question asked of them, then the coherence of replies (28) and (29) are additional counterexamples to DBI. IGN confronts no difficulty because (27) is decidedly incoherent.

What the knowledge-centric view of hedging clarifies is why the various completions of the DECLINE SCHEMA are coherent or not. Though different from the discourses we presented, declining discourses that complete the schema qualify as hedged discourses. They are discourses in which a speaker presents an answer to $Q$ but attenuates the strength with which that answer is presented by indicating that they occupy a position weaker than knowledge. Accordingly, (27) is incoherent for the reason that you cannot hedge by representing knowledge. Likewise, (28) and (29) are coherent because they are interpreted as hedging discourses.

\section{The aim of inquiry}

Wide-scope norms that prohibit being in a particular state during an activity require further explanation. It needs to be detailed what it is about the states or activities that prohibits their joint adoption. Consider the prohibition against being drunk while driving. That drinking impairs driving is what explains why one ought not do both. Regardless of what norm on inquiry is endorsed, something needs to be said regarding how belief or knowledge is connected to inquiry such that it is off limits to do both. Call this the CONNECTION LACUNA.

The connection can be made by pairing IGN with the view that knowledge is the aim of inquiry. In recent work, this view can be found in Williamson (2000), Schaffer (2005), Whitcomb (2010), Kappel (2010), Kelp (2011, 2014, forthcoming), Millar (2011), Rysiew (2012), and even Friedman $(2017,322)$ who writes that "the point or purpose or aim of opening [a question] is... to improve our epistemic standing on some matter-to settle a question and to come to know." We will shortly canvass two ways to arrive at the conclusion that knowledge is inquiry's aim. The first proceeds via reflection on the nature of inquiry. The second proceeds via reflection on the nature of knowledge. The point of this exercise is not to endorse any particular motivation for the conclusion that knowledge is the aim of inquiry. Our goal is just to reveal a natural way in which IGN alone can satisfy the CONNECTION LACUNA.

Taking an idea from Maitra (2011), we propose that, when activities have a goal or purpose, norms governing that activity are generated to facilitate the fulfillment of that goal. Consider professional basketball. The goal of winning by scoring the most points in the time allotted generates prohibitions on play like Do not let the shot clock expire without taking a shot and Do not shoot mid-range jumpers. These are not constitutive norms that determine what basketball is as a competitive activity. But they direct players towards the goal of winning by regulating their on-court behavior. Players who violate these prohibitions are liable to blame or to be benched for not playing the game to win.

The activity of inquiry is no exception. If its goal is knowledge in a complete answer, we would expect inquiry to have one or more norms involving knowledge. For example, inquiry, given its goal, might be regulated by norms corresponding to when to initially start inquiry like if you know $p^{Q}$, do not start inquiring into $Q$. Or it might be governed by norms corresponding to when to terminate inquiry such as stop inquiring into $\mathrm{Q}$ once you know $p^{\mathrm{Q}}$. These are undoubtedly both controversial 
norms but they are pretty boring and mundane if knowledge is the aim of inquiry. Consider basketball again. It plausibly has similar initiation and termination norms such as Stop playing basketball once you have scored the most points in the time allotted. Accordingly, a wide-scope norm like IGN is generated if knowledge in the complete answer is the aim or purpose of inquiry. The initiation and termination norms just mentioned are one intermediary step from inquiry aiming at knowledge to IGN. ${ }^{15}$ The CONNECTION LACUNA is thereby fulfilled. One ought not inquire into $Q$ and know $p^{Q}$ because achieving knowledge is the point of inquiring into $Q$. Insofar as an activity's aim is achieved, the activity terminates because its purpose is fulfilled. There would be no point to continuing the activity. Nor would there be any purpose in initiating the activity.

What about DBI? We do not have a similar path to closing the CONNECTION LACUNA. Belief often falls short of knowledge. As a result, mere belief cannot on its own satisfy inquiry's aim and hence cannot on its own render inquiry improper. Belief is but a doxastic step in the direction of achieving inquiry's aim. In what follows, we develop this point in further detail by considering two reasons one might maintain that achieving knowledge is inquiry's aim.

\subsection{Inquiry and the desire to know}

The kind of inquiry that has been our focus is not simply a mechanical search for an epistemic good. Rather, it is the sort of inquiry that is guided by an interrogative attitude, an attitude which typifies an agent's sincere interest in answering the question at issue. Nonetheless it is still natural to analyze this sort of sincere interest in terms of a desire for an epistemic good. But what sort of epistemic good is being desired when one has a sincere interest in answering a question? It is natural to suppose, as many others have, that the answer is knowledge. To put it another way, sincerely inquiring agents desire to know the answers to their questions (Pierce 1998, Loewenstein 1994, Williamson 2000, Whitcomb 2010, a.o.). ${ }^{16}$ Discourses like (30) and (31) provide reason to think as much.

(30) \# Even though I wonder who was at the party, I don't want to know who was there.

(31) I'm curious about whether there is milk or kefir in the fridge.

${ }^{15}$ We will not argue in this paper that one properly terminates an activity if and only if the goal of that activity is attained. Though attainment seems to ensure proper termination, proper termination may not guarantee attainment. For activities with a goal or aim that can be put along a scale, it is plausible that some activities allow proper termination at attainment and at some lower point on the scale. Were DBI correct, one might hypothesize that inquiry fits this description. Knowledge is its aim, but full belief sets the minimum threshold for proper termination. But two observations about this hypothesis are worthwhile. First, the CONNECTION LACUNA would still remain. An explanation would still be owed for why one can properly terminate inquiry at a lower point on the scale. Second, the hypothesis would need to distinguish QUITTING from PROPER TERMINATION. To illustrate the distinction, consider a chess player who walks away from a game before its completion because they are bored or see no way to win. Such a player quits as opposed to properly terminates the game. The distinction matters because it is conceivable that agents who stop inquiry at full belief are quitting as opposed to properly terminating: they see no way to arrive at knowledge, or they are practically deterred.

${ }^{16}$ Friedman (2013) argues against analyzing IAs like curiosity as metacognitive states like desires to know. We do not assess her case here. But note that even if IAs are not identical with metacognitive states, inquiry might still require a metacognitive state to accompany an IA. 
Would you like me to let you know?

\# Definitely not.

The discourses are defective. We find an easy explanation why if inquiry requires a desire to know. The discourses ring defective because they exhibit an agent inquiring into a question $Q$ for which they do not desire to know the answer. ${ }^{17}$

With the supposition that inquiry requires a desire to know, we have a straightforward path to satisfying the CONNECTION LACUNA with IGN. Desires aim at their fulfillment. Accordingly, inquiry aims at knowledge because that is what satiates the inquisitive agent's desire to know. Framed in terms of initiation and termination, it is not coherent to begin having a desire when that desire is already fulfilled or to continue having desire after it is fulfilled. Applied to the desire to know, it is not coherent to desire to know $p^{Q}$ and to know $p^{Q}$. The norm IGN captures that impropriety.

The same path cannot be followed by DBI. The desire to know is not satisfied by belief, especially when one does not regard the belief as knowledge. An illustration is given by Whitcomb $(2017,160)$. He notes that (33) is uncooperative.

(32) Did it freeze last night?

(33) I don't know the answer, but I'm willing to help. Go talk to John. There's a proposition he believes to be the answer.

One way of glossing what is uncooperative about the response is that it does not give the agent what they want. What they want is knowledge of whether it froze last night. But redirecting to a third-party who merely believes, the response fails to empower the inquiring agent to fulfill that desire. As an analogy, suppose you had a late night craving for kefir. It would be similarly uncooperative to recommend that you visit a closed grocery store. Cooperative responses help agents attain their desires. Accordingly, the CONNECTION LACUNA remains for DBI given the supposition that a desire to know animates inquiry. Belief is just not enough epistemically.

\subsection{Inquiry and the function of knowledge}

One way to glean insight into matters epistemological is by investigating the function or purpose of our epistemic concepts. The locus classicus of this approach is Craig (1990). He takes the function of knowledge to be tagging reliable informants. But many amend Craig's proposal to suggest that knowledge certifies an informant as having a strong enough epistemic position to terminate inquiry (Schaffer 2005,

${ }_{17}$ Desires conflict. The desire to know is no different. We submit that cases where an agent is inquiring into a question for which they do not want to know the answer-whether a partner is faithful, whether the calorie count of kefir is too high-are cases of conflicted desires. In inquiring, the agent desires to know the answer to their question, but they also desire to not know the answer because they are afraid of what it might be. 
Kappel 2010, Kelp 2011, Rysiew 2012). ${ }^{18}$ In considering other epistemic positions, Rysiew $(2012,278)$ writes:

Given that there are plenty of terms available for picking out informants of one or another degree of reliability, what's special about 'know(s)'? Why do children acquire that concept so early in life (Bartsch and Wellman 1995)? And why is 'know(s)' one of our ten most common verbs (Davies and Gardner 2010, cited in Nagel 2010: 408)? The certification view suggests an answer: unlike most epistemic and quasi-epistemic terms ('reliable', 'justified', 'rational', etc.) 'knows' does not admit of degrees; unlike most of these terms too, it is both factive (like the straight 'p') and evaluative; and unlike 'certain' (as applied to a proposition), say, given a broad non-skeptical orientation it's clear that the standards for its correct application are neither too high to often be met nor much more demanding than what our ordinary purposes require. In view of this combination of features, 'knows' appears to be very well suited for playing the certification role, a role calling for a certain finality or categorical effect.

Rysiew's guiding idea is that various properties of the verb knows - its universality and its early childhood acquisition relative to other epistemic terms - as well as of knowledge - its non-degreedness, factivity, and evaluativity - motivate that knowledge attributions certify when an agent has reached a point where no further investigation by that agent is needed for others to rely on their epistemic labor. Kappel (2010) reasons a little differently. One way to understand his point is that there is something distinctive about what inquirers do when they close inquiry. Inquiries are taxing activities and it's always possible for inquirers to seek additional evidence. Inquirers are therefore interested in being in a position where they may rely on their answers to questions without having to inquire into the matter any further. For Kappel, the concept of knowledge certifies that further inquiry is not required.

Suppose the role of knowledge is what Rysiew, Kappel, and others theorize. It follows that knowledge is the aim or goal of inquiry. Agents can terminate inquiry only when they have achieved the activity's aim: that is, only when they have come to occupy the epistemic position certifying as much. Only after knowledge of a question's answer is attained is there no longer cause to further investigate various answers. Otherwise, it is worthwhile for agents to continue accumulating evidence for and against answers to their inquiry's question.

The certification view equips IGN to navigate the CONNECTION LACUNA. Knowing $p^{Q}$ certifies that inquiry into $Q$ is closed. To continue an activity after it is certifiably completed is incoherent. Consider the incoherence of We scored the most points in the time allotted, but I am going to try to win the game. That is incoherent in the same manner as I know that there is leftover milk, but I wonder whether there is leftover milk. Both discourses betray a deep confusion about the goal-directed activity in which the speaker is participating. As a purposive norm, IGN prohibits such incoherence within inquiry.

It is difficult again to see how DBI can satisfy the CONNECTION LACUNA given what we have supposed. If knowledge certifies that inquiry is closed, a position

${ }^{18}$ There are other ways on which knowledge might be question-relative which do not require a function-theoretic approach to epistemology. See Hookway (1996) and Schaffer $(2005,2008,2015)$. The significance to IGN and the CONNECTION LACUNA is presumably the same. For reasons of space, we overlook these theories. 
short of knowledge like belief would not perform the same inquiry-theoretic role. The point can be made in terms of double-checking. If knowledge uniquely certifies that further double-checking is unnecessary, weaker positions still properly compel double-checking.

\section{Exhaustivity}

The sort of inquiry we have been studying - inquiry guided by some interrogative attitude - is governed by a variety of norms that constrain how inquirers must conduct themselves. When it comes to which epistemic positions are permissible to occupy while engaged in inquiry, we have so far argued that IGN, a prohibition against inquiring and knowing, has explanatory primacy. We have made our case by contrasting IGN with DBI, a norm defended by Friedman (2019a). The case had two parts. First, we argued that data motivating DBI can be explained by IGN. There is no explanatory work for a weaker norm to do. Second, we argued that DBI has problems that IGN does not.

A parallel case can be made against any norm that prohibits inquiring while occupying an epistemic position weaker than knowledge. In particular, consider the problems that afflict DBI. The first was that it mistakenly identifies hedging during inquiry as prohibited. But it is not. This problem easily generalizes. We do not just hedge by indicating belief. Often we hedge by indicating a stronger position. For example, (34) and (35) are variants on our earlier examples of hedging that indicate a stronger position.

(34) I am almost / nearly certain there is leftover milk. However, I forgot my glasses and it was hard to tell if what I saw was milk or kefir. So I don't really know. I'm gonna find my glasses and then check again.

(35) I am extremely confident that only Borya was at the party. But I don't know that. So let's ask Kolya, the party's host, to figure out who was at the party.

Neither discourse is defective. Both coherently display where an agent might find themselves during inquiry. But various norms stronger than DBI but weaker than IGN in what position is prohibited will mishandle such discourses. A similar point can be made with Whitcomb's (2017) declining data.

The second problem with DBI was that it could not resolve the connection lacuna in conjunction with the view that knowledge is the aim or goal of inquiry. One's continued participation in an activity which has its goal fulfilled is incoherent. If knowledge is the aim of inquiry, then inquiring into $Q$ while knowing $p^{Q}$ is incoherent. IGN captures such incoherence as a purposive norm. But a similar explanation cannot be given for any norm involving a weaker position than knowledge. When you have yet to achieve the goal of an activity, you may coherently continue to participate in that activity. As such, arriving at justified belief, near certainty, or what-have-you is not enough for incoherence. Knowledge has not yet been achieved.

Of the two problems, the second is perhaps less threatening for DBI and similar norms. One may just deny that explaining the CONNECTION LACUNA has to be closed while supposing that knowledge is inquiry's aim. One can even mirror the 
explanation we gave of the CONNECTION LACUNA by supposing that $V$ is inquiry's aim where $V$ is whatever epistemic position a rival norm prohibits one from occupying while they inquire. But we are skeptical about a mirrored explanation because we are optimistic about the reasons highlighted above for why inquiry has its goal achieved with knowledge. Views according to which inquiry involves a desire to have belief or where function of belief is certifying inquiry's termination strike us as non-starters.

The type of inquiry we have been examining is tightly connected with the suspension of judgment and the nature of belief. ${ }^{19}$ We have not discussed these topics. But what we have argued is that the question of which conduct is epistemically prohibited during inquiry carries consequences for these other topics. For example, what we have argued is at odds with the view that inquiry requires suspension towards a question $Q$ and that suspension is incompatible or improper alongside belief that $p^{Q}$ (Friedman 2017). Hedging in inquiry shows that one can properly inquire and believe. Accordingly, either inquiry does not require suspension or suspension is compatible or proper with belief. We leave the reader on their own to untangle these issues. ${ }^{20}$

\section{References}

Archer, Avery (2018). Wondering about what you know. Analysis 78 (4), 596-604.

Adler, Jonathan (2002). Belief's Own Ethics. Cambridge: MIT Press.

Asher, Nicholas (2000). Truth Conditional Discourse Semantics for Parentheticals. Journal of Semantics 17 (1), 31-50.

Benton, Matthew A. (2011). Two more for the knowledge account of assertion. Analysis 71 (4), 684-687.

- - - and van Elswyk, Peter (2020). Hedged Assertion. The Oxford Handbook of Assertion. (ed.) S. Goldberg. Oxford: Oxford University Press.

Bilgrami, Akeel (2006). Self-Knowledge and Resentment. Cambridge: Harvard University Press.

Blaauw, Martijn (2012). Reinforcing the knowledge account of assertion. Analysis 72 (1), 105-108.

Burge, Tyler (1996). Our Entitlement to Self-Knowledge. Proceedings of the Aristotelian Society 96, 91-116.

Craig, Edward (1990). Knowledge and the State of Nature: An Essay in Conceptual Synthesis. Oxford University Press.

DeRose, Keith (1992). Contextualism and Knowledge Attributions. Philosophy and Phenomenological Research 52 (4):913-929.

- - (2002). Assertion, knowledge, and context. Philosophical Review 111 (2), 167-203.

${ }^{19}$ See Friedman (2017, 2019a), Staffel (2019), Miracchi (2019), McGrath (forthcoming), and Raleigh (forthcoming) for recent work linking inquiry to suspension and the nature of belief.

${ }^{20}$ For helpful comments and conversation, we thank participants at the Nature of Inquiry Workshop at Agnes Scott College. In particular, we are indebted to Jane Friedman, Dennis Whitcomb, Jared Millson, Dunja Šešelja, Will Fleisher, Zach Barnett, and Arianna Falbo. Thanks are also due to Joshua Spencer, Chris Willard-Kyle, and two anonymous referees at this journal. 
Fraser, Bruce (2010). Pragmatic competence: the case of hedging. New Approaches to Hedging. (eds.) G. Kaltenöck, W. Mihatsch, and S. Schneider. Emerald. pp. 15-34.

Friedman, Jane (2013). Question-directed attitudes. Philosophical Perspectives 27: $145-174$

-—— (2017). Why suspend judging? Noûs 51 (2), 302-326.

-_- (2019a). Inquiry and Belief. Noûs 53 (2), 296-315. (2019b). Checking again. Philosophical Issues 29, 84-96.

Gajewski, J. R. (2007). Neg-raising and polarity. Linguistics and Philosophy 30(3), 289-328

Hawthorne, John, Rothschild, Daniel, \& Spectre, Levi. (2016). Belief is weak. Philosophical Studies 173 (5), 1393-1404.

Hookway, Christopher (1996). Questions of context. Proceedings of the Aristotelian Society 96, 1-16.

Jackson, Elizabeth (2020). Belief, credence, and evidence. Synthese 197, 5073-5092.

Kappel, Klemens (2010). On Saying that Someone Knows: Themes from Craig. Social Epistemology. (eds.) A. Haddock, A. Millar, and D. Pritchard. Oxford: Oxford University Press.

Kelp, Christoph (2011). What's the point of "knowledge" anyway? Episteme 8, 53-66.

- - (2014). Two for the knowledge goal of inquiry. American Philosophical Quarterly 51, 227-32.

- _ - and Simion, Mona (2020). The C account of assertion: A negative result. Synthese 197, 125-137.

- - - (forthcoming). Inquiry, knowledge and understanding. Synthese.

Loewenstein, G. (1994). The Psychology of Curiosity: A Review and Reinterpretation. Psychological Bulletin 116(1), 75-98.

Maitra, Ishani. (2011). Assertion, norms, and games. Assertion: New philosophical essays. (eds.) J. Brown and H. Cappelen. Oxford: Oxford University Press.

Malamud, S.A. and T. Stephenson (2015). Three ways to avoid commitments: declarative force modifiers in the conversational scoreboard. Journal of Semantics 32: 275-311.

McGrath, Matthew (forthcoming). Being neutral: Agnosticism, inquiry and the suspension of judgment. Noûs.

McCready, Elin (2014). Reliability in Pragmatics. Oxford University Press.

McGlynn, Aidan. (2014). Knowledge First? Palgrave Macmillan.

McKinnon, Rachel and Turri, John (2013). Irksome assertions. Philosophical Studies 166 (1), 123-128.

Millar, A (2011). Why knowledge matters. Proceedings of the Aristotelian Society 85, 63-81.

Millson, Jared (forthcoming). Seeking confirmation: A puzzle for norms of inquiry. Analysis.

Mirrachi, Lisa (2019). When evidence isn't enough: Suspension, evidentialism, and knowledge-first virtue epistemology. Episteme 16 413-437.

Murray, Sarah. (2017). The Semantics of Evidentials. Oxford: Oxford University Press.

Peirce, C. S. (1998). The Essential Peirce: 1893-1913. Indiana University Press.

Raleigh, Thomas (forthcoming). Suspending is believing. Synthese.

Romoli, J. (2013). A scalar implicature-based approach to neg-raising. Linguistics and Philosophy 36(4), 291-353

Rothschild, Daniel (forthcoming). What it takes to believe. Philosophical Studies. 
Rooryck, Johan. (2001). Evidentiality, Part I. Glot International 5, 125-133.

Rysiew, Patrick (2012). Epistemic Scorekeeping. Knowledge Ascriptions. (eds.) J. Brown, and M. Gerken. Oxford: Oxford University Press.

Schaffer, Jonathan (2005). Contrastive Knowledge. Oxford Studies in Epistemology 1 (2005), 235-7.

- - (2008). Knowledge in the image of assertion. Philosophical Issues 18(1), 1-19.

- _ - (2015). Lewis on knowledge. A companion to David Lewis. (eds.) J. Schaffer and B. Loewer. Wiley.

Slote, M.A. 1979. Assertion and belief. In J. Dancy (ed.), Papers on Language and Logic. Keele: Keele University Library.

Staffel, Julia (2019). Credences and suspended judgments as transitional attitudes. Philosophical Issues 29 (1), 281-294.

Turri, John (2010). Prompting challenges. Analysis 70 (3), 456-462.

Urmson, J. O. (1952). Parenthetical verbs. Mind 61 (244), 480-496.

van Elswyk, Peter (forthcoming). Representing knowledge. The Philosophical Review. Whitcomb, Dennis (2010). Curiosity was framed. Philosophy and Phenomenological Research 81 (3), 664-687.

_- - (2017). One kind of asking. Philosophical Quarterly 67 (266), 148-168.

Williamson, Timothy (2000). Knowledge and its Limits. Oxford University Press. 